\title{
Artistic Acupuncture Missions: Penetrating the Public Space
}

\author{
Herman Bashiron Mendolicchio \\ University of Barcelona, Spain \\ hmendolicchio@ub.edu
}

\begin{abstract}
9 places in Europe, 9 artists and collectives, 9 hosts (European Festivals of Art in Public Space) and one multi-layered artistic framework and methodology -the acupuncture- to respond to specific challenges related to urban renewal, social justice or cultural identities. The IN SITU Network has developed this ambitious project in collaboration with its partners between autumn 2018 and the end of 2019. The artists have explored different territories and got to know their specific challenges by engaging in conversation with a wide range of stakeholders. After a short residency period the artists come up with their imaginative proposals, based on a fresh look and inquiry. Built on the analysis of the 9 artistic acupuncture missions, this portfolio aims at focusing on the innovative methodology and strategies employed by the artists in different and complex contexts. The text explores how the artists, in collaboration with their hosts, have developed their creative missions and interpreted the changing meanings, values and functions of public space.
\end{abstract}

Keywords: artistic acupunctures, public space, urban renewal, social justice, cultural identities

To cite this article:

Mendolicchio, H. B. (2020) Artistic Acupuncture Missions: Penetrating the Public Space, The Journal of Public Space, 5(4), 209-220, DOI 10.3289I/jps.v5i4.1383

This article has been reviewed by the Editors and accepted for publication in The Journal of Public Space.

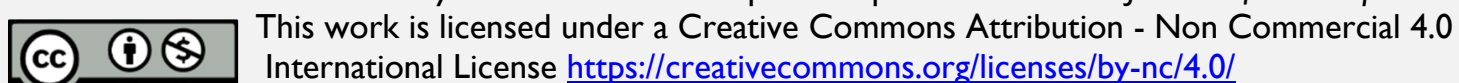
International License https://creativecommons.org/licenses/by-nc/4.0/ 


\section{Introduction}

The diverse characteristics of public space, for its own mutable essence, are in a constant process of development and change. Public space needs, structures and dynamics vary according to, among others, the geographical, climatic, cultural, technological, political and economic differences that we might find in any place and time.

Since the start of the new millennium, and since the widely shared experience of globalization, we could find several definitions that have been applied to public space, with the clear purpose of exploring its traits and highlighting its virtues, features and functions. Among the most interesting views and reflections that emerge from the sphere of political analysis, we can stress the meaningful link between public space and the development of human rights.

In the 2019 report prepared by the UN Special Rapporteur in the field of cultural rights, Karima Bennoune, we find that: "Public spaces are conduits for realizing human rights for all. The human rights framework should be applied to the design, development and maintenance of public spaces in urban, rural, natural and digital spaces. If States, international organizations and the international community do not take the issue of public space seriously and fail to understand it as a basic question of human rights, it will be impossible to fulfil cultural rights, and indeed many other universal human rights" (Bennoune, 2019, p. 21).

A public space where human rights can be realized is a space of interdependencies and one where different models of coexistence can be imagined and practised.

Contemporary studies about the role of public space point out these fundamental aspects related to the search for equality and the recognition of citizens' rights.

According to the Charter of Public Space, adopted in Rome in 2013 as one of the main outcomes of the Biennale Spazio Pubblico: "Public space must be the place where citizenship rights are guaranteed and differences are respected and appreciated" (Charter of Public Space, 2013, p. 4).

Echoing the spirit of the Charter, the architect Pietro Garau asserted that: "In public spaces we are all equal, in the sense that we can all exercise our shared right to the city without having to display our social status" (Garau, 20I4, p.6).

The attention and reflection towards public space are currently at the top of the agenda of several UN agencies (e.g. the UN-Habitat), and other international organizations like the UCLG (worth mentioning the work done by the Agenda 2I for Culture), which are all focusing on its key role in the achievement of the Sustainable Development Goals.' A recurrent approach asserts that public space should facilitate a dynamic environment for the expression of cultural diversity and cultural values, but, as observed by Jordi Baltà Portolés: "Beyond the notion of 'access to culture', which may often entail passive reception of cultural works 'produced' by artists, the more active notion of 'participation' should prevail. (...) In addition to taking part in specific cultural activities

I There is a growing literature about the links between public space and the SDGs. See, among others: UCLG, (2015). Culture 21: Actions. Commitments on the role of culture in sustainable cities. Available at: http://agenda2Iculture.net/sites/default/files/files/culture2I-actions/c2I 015 en.pdf; and: Kristie Daniel (2016), Public Spaces: A key tool to achieve the Sustainable Development Goals, HealthBridge. Available at: https://healthbridge.ca/images/uploads/library/Final_Electronic.pdf [Accessed I0 September 2020] 
such as, for example, the creation of new narratives and works, the right to take part in cultural life requires active involvement in decision-making and in the management of cultural processes and activities" (Baltà Portolés, 2019, p. 119).

Participation, collaboration, social and community engagement, enhancing citizens interactions and synergies, recognizing interdependency, developing new models of horizontal design and governance, processes of listening and co-creating, are therefore among the different notions and understandings currently being used to analyse public space and its complex ecosystem.

Then, if we move from a theoretical to a more practical approach, what are the methodologies to penetrate into and analyse the challenges of public space and its multidimensional ecosystem? What are the tools to engage with a mutable and evolving context in which a set of very diverse agents and stakeholders operate and interact? From the artistic, architectural and creative field, the IN SITU Network has approached an existing and inspiring methodology and practice that opens up other formats to penetrate into the different layers of public space and its multiple challenges: the acupuncture.

Drawing on a process which started in the field of urban planning and social participation, ${ }^{2}$ and conceptually linked to an ancient oriental therapeutic practice originating in China, the acupuncture methodology focuses on locally oriented interventions, with different strategies aiming at involving citizen participation in the ongoing inquiry and transformation of public space.

As described by the artist Jeanne van Heeswijk: "[Artistic interventions in public space] are a form of urban acupuncture (hit and run tactics) that will allow the sensitive places in our society to emerge and the blocked relational energies flow again" (Van Heeswijk, 20II).

By imagining the artist as a needle that can activate and connect multiple points in the body of public space; and by imagining the artistic process as needles that can stimulate and provide a different reaction and understanding about a specific problematic in public space, the IN SITU network has conceived and developed the project Artistic

Acupuncture in Europe. Nine different members of the network, located in the different countries involved in the project [La Strada Festival, Austria; Lieux Publics, France;

Artopolis Association - PLACCC Festival, Hungary; Teatri ODA, Kosovo; Fira Tàrrega, Spain; Provinicaal domein Dommelhof, Belgium; 4+4 Days in Motion, Czech Republic; Oerol Festival, Netherlands; Østfold Internasjonale Teater, Norway] have taken part in the process and have invited a specific artist -chosen for his/her own creative vision and practice- to explore its context and territory and to respond creatively to a local problematic.

Focusing on three main topics - social justice, cultural identity and urban renewal Artistic acupuncture for places in Europe is an attempt to show how foreign artists, coming from different European countries, can bring a renewed, relevant understanding of societal issues. It is asserted that their observations can create new meaning and shift the perspective on key topics endemic in contemporary societies.

2 See, among others: Jaime Lerner (2014). Urban Acupuncture, Island Press; Darren O'Donnell's (2002). Social Acupuncture, Coach House Books; and: Helena Casanova and Jesús Hernández (2015). Public Space Acupuncture. Strategies and Interventions for Activating City Life, Actar. 


\section{A European journey through the Acupuncture missions}

A group of different artists, between autumn 2018 and the end of 2019, prepared their luggage and began their journeys to their short and intense acupuncture missions. With a traveller's approach and gaze, they set out to singular and mostly unknown territories, ready to explore and dig into them, and counting on the support of the IN SITU members that were acting as their 'local guides'.

Focusing on a deep research process, developed by connecting with the multiple agents and realities of each local ecosystem, the artists were asked to come up with a creative response, adopting the imagination of an utopian artistic project.

Graz (Austria), Marseille (France), Budapest (Hungary), Pristina (Kosovo), Tàrrega (Catalonia), Genk (Belgium), Prague (Czechia), Terschelling (Netherlands) and Moss (Norway) are the 9 cities, the 9 different contexts - with very diverse challenges, landscapes, languages, social dynamics and cultures - in which the Acupuncture missions took place. Equipped with their sensitivity, imagination, vision and creative tools, the artists travelled around the hidden corners of each place, meeting with people, engaging in conversations and trying to enter deeply - and through alternative entry points - into the veins of the specific situation and problematic related to each context. The development and the innovative approaches and strategies of the acupuncture methodology have opened new spheres and layers of practice, research and contemplation, enlarging and deepening the field, the function and the understanding of art in public space.

By designing a European journey - reaching and touching multiple and diverse points of the body of the continent - through which the artists and the members of the network have engaged profoundly in an exercise of fruitful encounters, explorations and conversations, the whole Acupuncture project gave way to unexpected processes and discoveries. Focusing on the importance of the artistic process itself - beyond its possible results - the acupuncture missions triggered an inspiring dynamic in which the artists investigated the relational ecosystem of each public space, connecting and discussing with a wide range of citizens and stakeholders, by means of an ethnographic and cartographic methodology.

According to James Moore, curator-producer at $Ø$ stfold Internasjonale Teater, representing the IN SITU member in Norway: "The systematic approach to investigating a particular question/theme/place with a foreign artist enables and obliges encounters and interviews with a broad spectrum of individuals. By interviewing people from both public sector and the civil society, with different professional fields, and with different perspectives and/or positions regarding the topic, we gained a rich and dynamic overview. This relates first and foremost to the mapping character of the Acupuncture exercise". ${ }^{3}$

Throughout this multifaceted as well as tailor-made process of research and creative practice, we can identify a number of specific elements and concepts useful for envisioning the current and future challenges in the field of art and activism in public space. We will try to summarize them in the following points:

3 Interviewed by the author. 25th May 2020. 


\section{- The future of cities and the cities of future}

Urban planning and city development should no longer be an issue for only a few stakeholders, but the citizens-residents' views and perspectives must become essential components that need to be taken into account. As stated in the UN report previously mentioned: "Authorities must establish specialized, cross-disciplinary professional teams responsible for the design, maintenance and conservation of public spaces that are welcoming for all and create mechanisms for citizen participation in the management of such spaces" (Bennoune, 2019, p. 23).

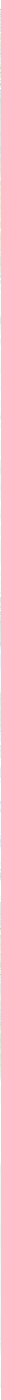

Figure I. Artistic Acupuncture, Graz - Reininghaus. Danae Theodoridou. Photo @La Strada Graz/ Nikola Milatovic

In the visionary Artistic Acupuncture developed by Danae Theodoridou in the area of Reininghaus in Graz; in the exploration of the post-industrial district of Csepel, Budapest, realized by Nada Gambier and Mark Etchells; or in the creative analysis of the urban renewal landscape in the city of Moss, carried out by Sjoerd Wagenaar; all the artists have addressed the challenging topic of urban regeneration, stimulating new ideas and perspectives. 


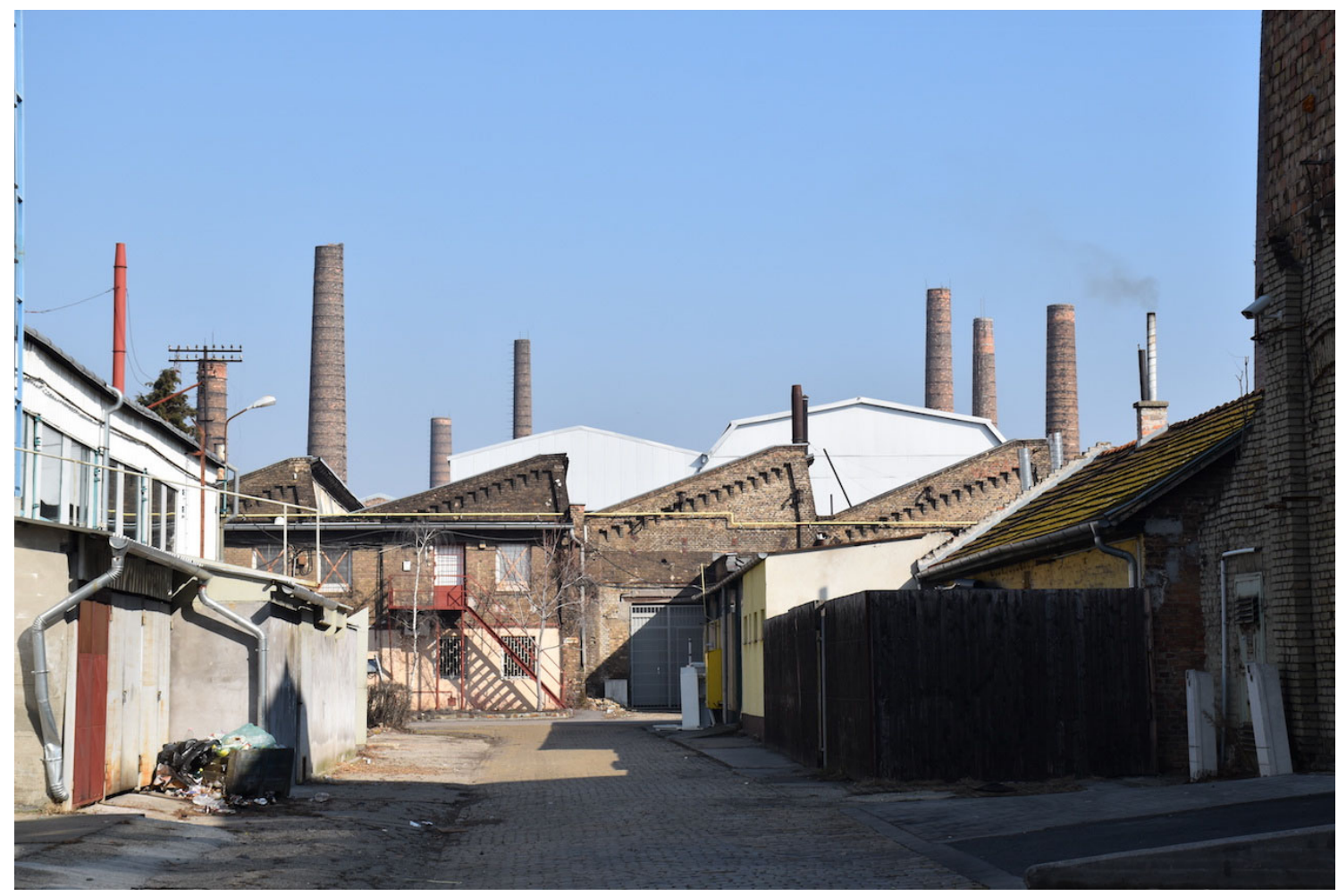

Figure 2. Artistic Acupuncture, Budapest - Csepel. Nada Gambier \& Mark Etchells. @Nada \& Co. Photo by Etchells/Gambier

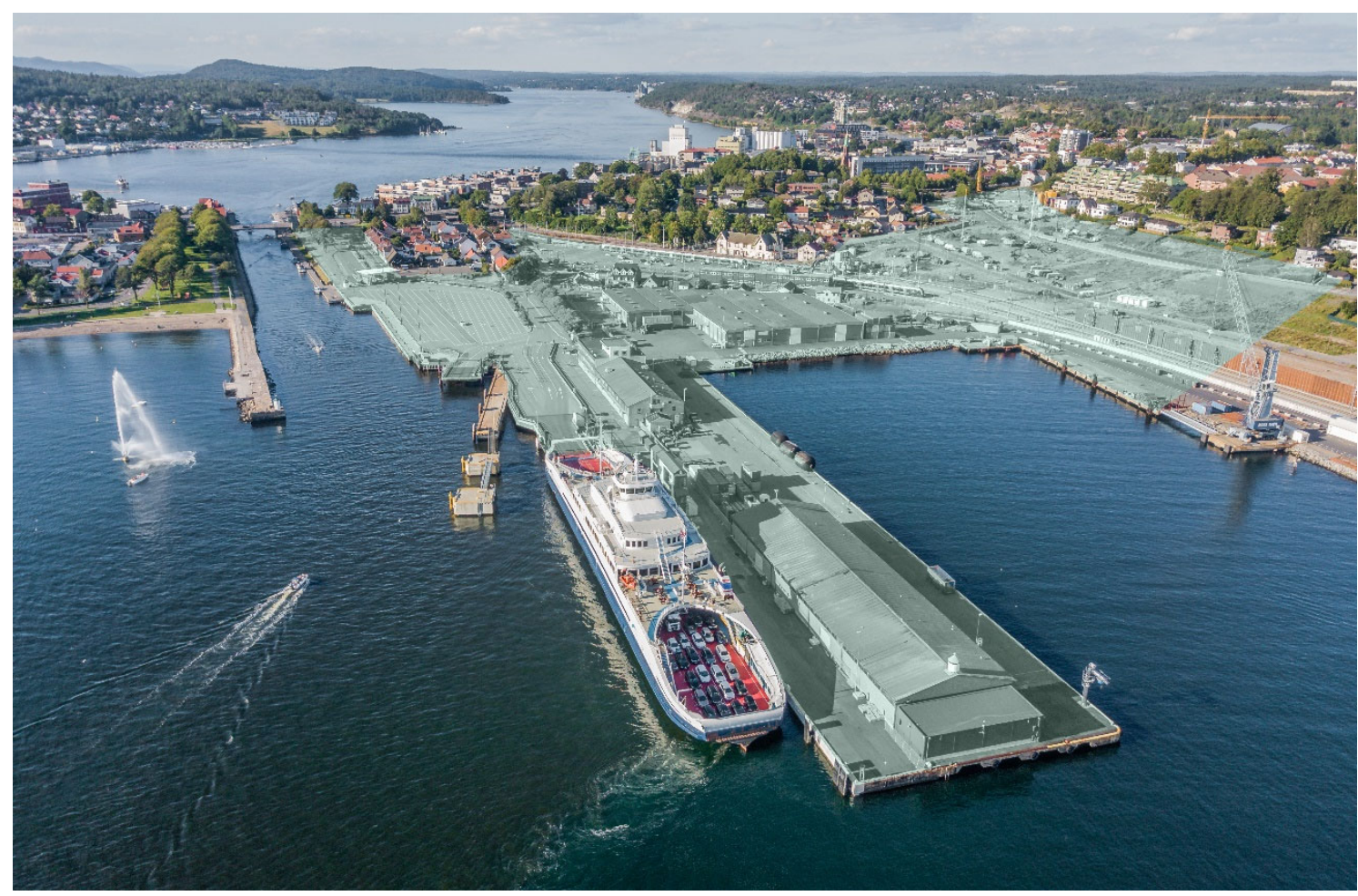

Figure 3. Artistic Acupuncture, Moss. Sjoerd Wagenaar. Photo $@$ Terje Holm 
A shift in public space design requires a creative approach: "Designing public spaces also means taking into account alternative and creative practices based on new techniques of communication and urban usage" (Charter of Public Space, 2013, p. 8), as well as a process of reversing the strategies: "Planning with a focus on public space means reversing this order and starting, rather than from the 'private city', from the 'public city'. It is the concept of public-space led planning" (Garau, 2014, pp 17-I8).

\section{- The right to the village}

It is time to claim the right to rural public space for a sustainable future, and it is important to consider the emergence of rural space beyond the simplistic discourse of contrast between centres and peripheries. Fostering urban-rural linkages; questioning models of production, distribution and consumption; reclaiming a new space for ecology and for environmental consciousness; and preserving the cultural spaces in rural areas, are some of the urgent matters to take into account related to this field. As demonstrated by the acupuncture mission of Deirdre Griffin in Tàrrega and its surrounding depopulated area, behind a curtain of distance, abandonment and depopulation, the rural areas unfold a deep wealth of knowledge, experience and values that need to be preserved.

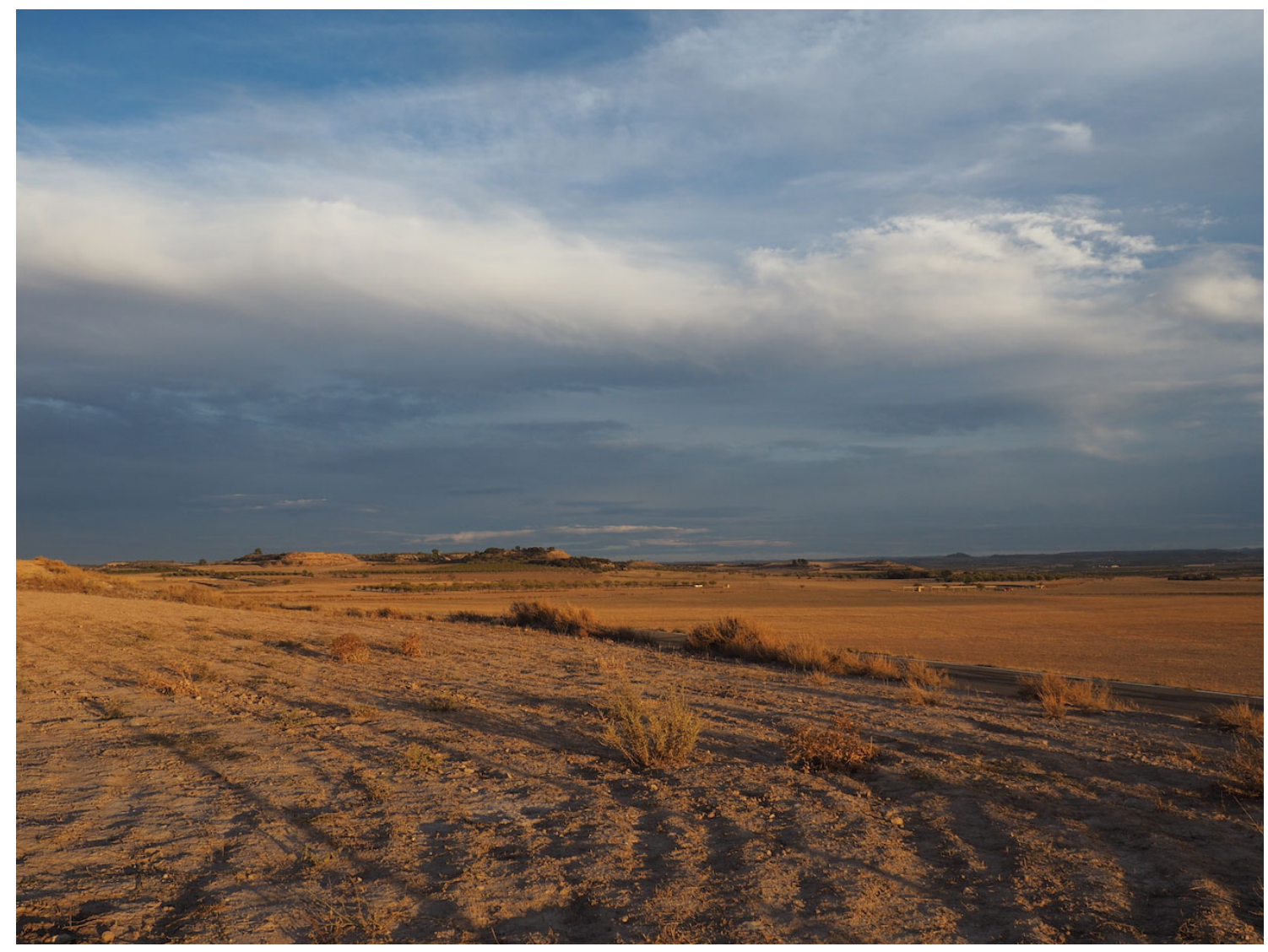

Figure 4. Artistic Acupuncture, Tàrrega. Deirdre Griffin. Photo (c) Maria Capell Pera

- Refreshing and resignifying the concept of heritage and monument The different components of history and heritage, their representation, meanings and functions, are neither static nor neutral issues, but also depend on shifts in economic 
and political power. For the acupuncture mission developed in Prague, the artist duo zweintopf (Eva Pichler and Gerhard Pichler) addressed the controversial question of political statements in public space and the role of con(temporary) monuments. Public space has always been identified as the main stage for the performance of political power, and monuments and sculptures are some of its most astonishing instruments.

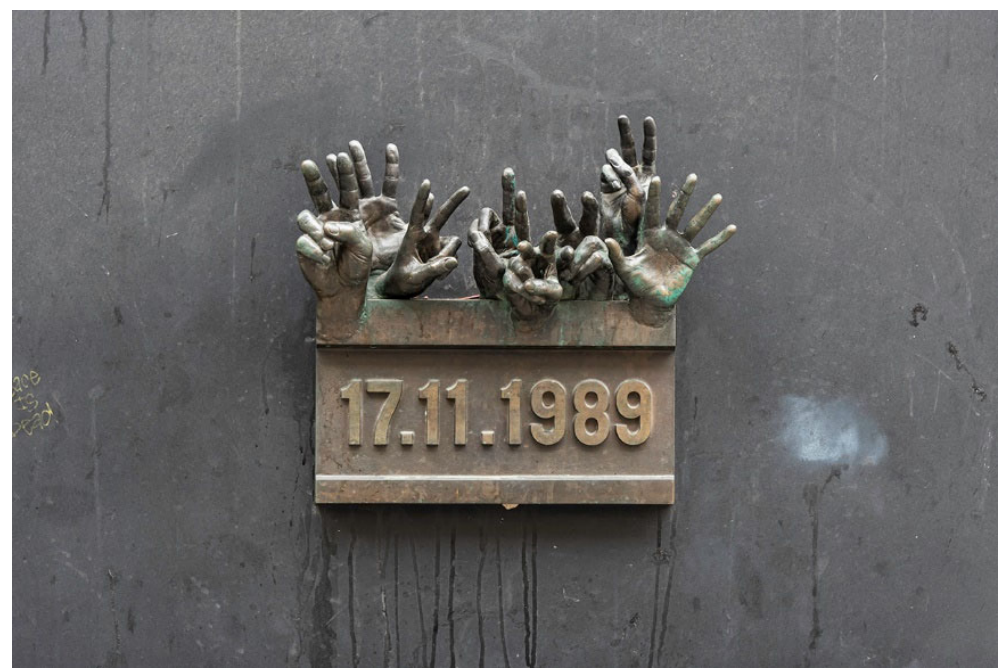

Figure 5. Artistic Acupuncture, Prague. zweintopf. Photo $\odot$ zweintopf

\section{- Culturally diverse, plural, inclusive, safe and utopian}

As previously analysed, public spaces have a fundamental role in the accomplishment of human rights and equality, but unfortunately, beyond the positive will and statements, we also know that many public spaces are the embodiment of the lack of justice, of fear and anxiety. With that in mind, the artist Maria Sideri developed her acupuncture project focusing on the place of women in public space in the city of Marseille.

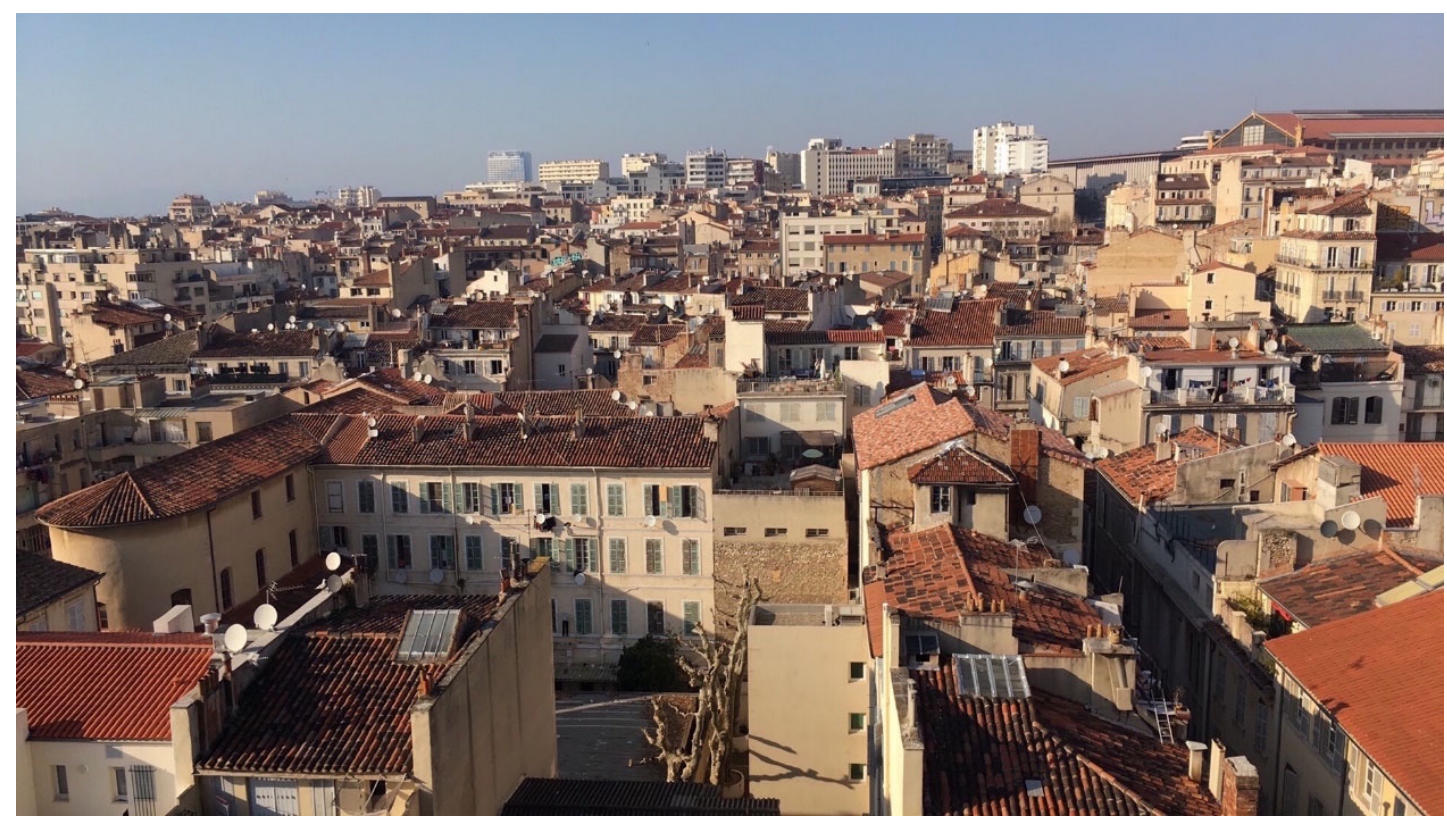

Figure 6. Artistic Acupuncture, Marseille. Maria Sideri. Photo @ Sideri 
As stressed in the UN report about safe public spaces: "When women and girls are not safe walking on city streets, selling their goods or shopping in marketplaces (...) it has a massive impact on their lives. Both the threat and the experience of violence affect their access to social activities, education, employment and leadership opportunities" (UN Women Report, 2017, p. I).

\section{- Sharing responsibilities and fostering co-existence}

Linked to the previous point, we can find different artistic approaches that emphasize how the public environment is a space of rights and duties and a space where different generations and communities co-exist in contemporary intercultural society.

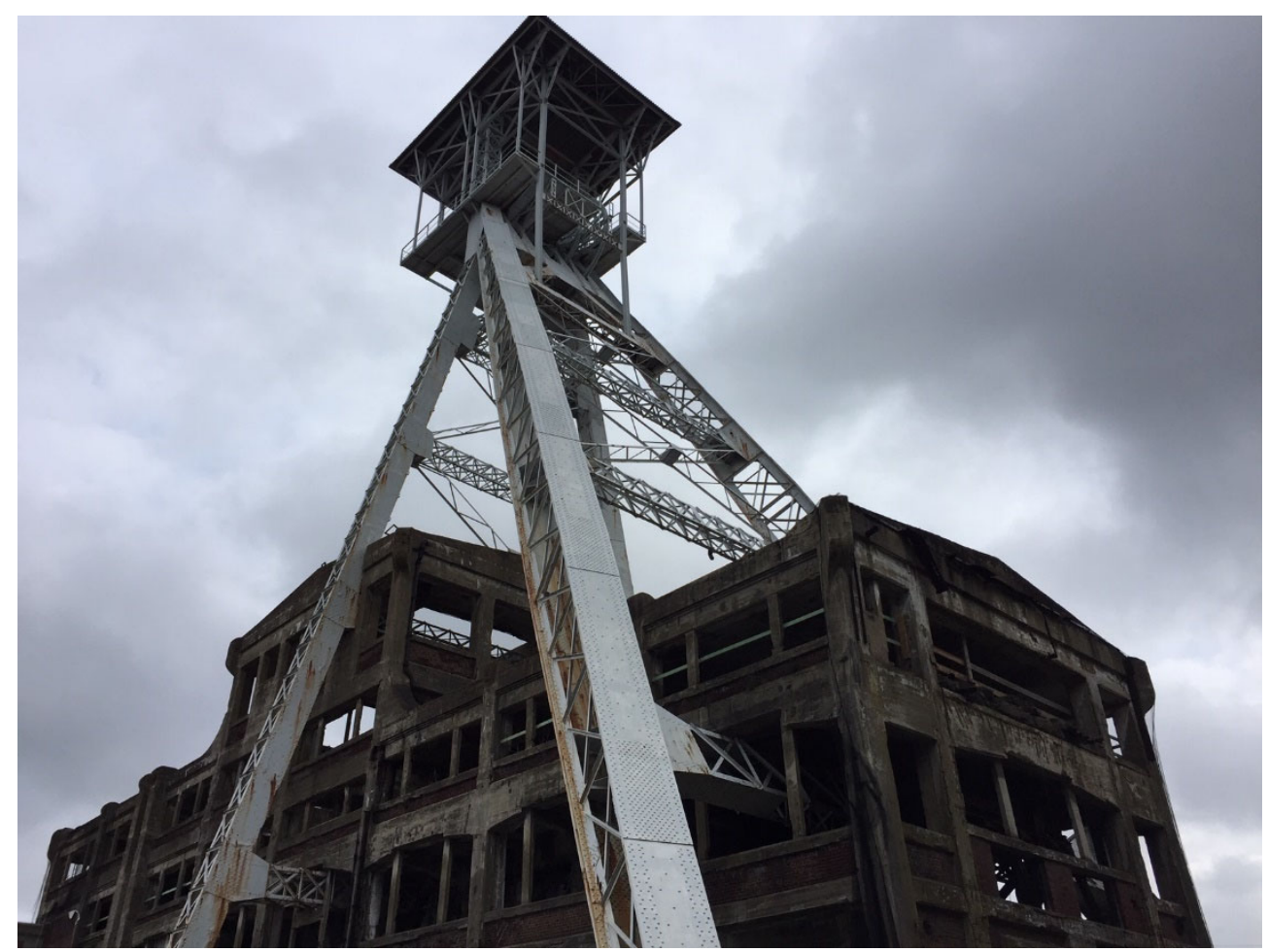

Figure 7. Artistic Acupuncture, Genk. Francesca Grilli. Photo @ Grilli

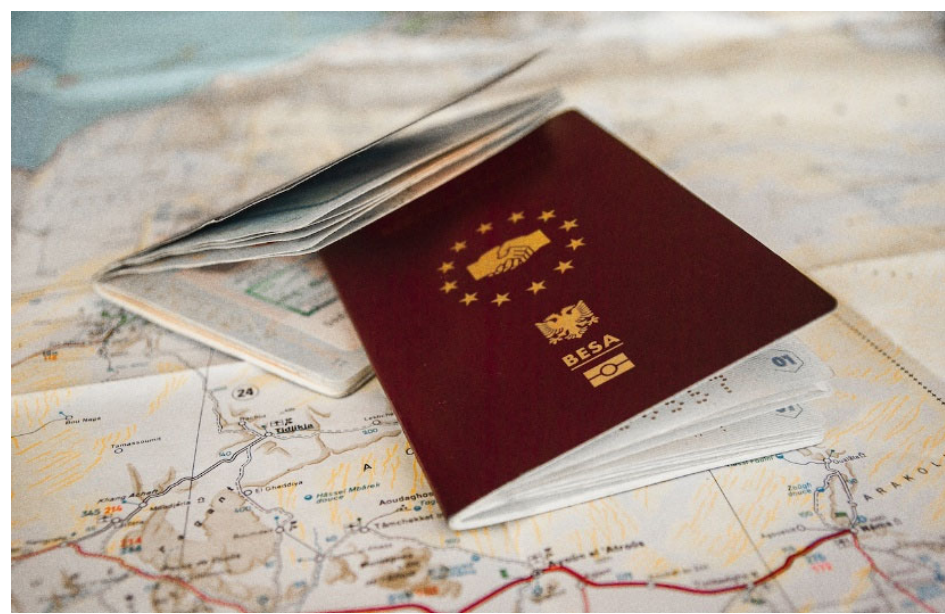

Figure 8. Artistic Acupuncture, Prishtina. Morten Traavik. Photo @ Traavik.info / BESA Project 2020 
Francesca Grilli, through her acupuncture mission in Genk, focused on issues related to the hybridity and the shifting cultural identity of the Belgian city. Morten Traavik explored the challenging frameworks of visa regulations, borders, mobility restrictions, immigration and integration issues in the EU, in the specific context of Kosovo.

\section{- Public space as the bridge between the local and the global}

Permanent inhabitants, temporary residents, transient and fleeting passers-by and visitors often walk through and share the same public space. Who does public space belong to? What are the mechanisms to bridge different needs and uses of the public space? How does the cultural identity of a place change due to the encounter between the global and the local? In her Acupuncture mission in Terschelling, Joanne Leighton interwove stories and experiences, focusing on the particular condition of this tiny Frisian island, which is both home to a small and permanent local community, and host to a huge influx of foreign visitors.

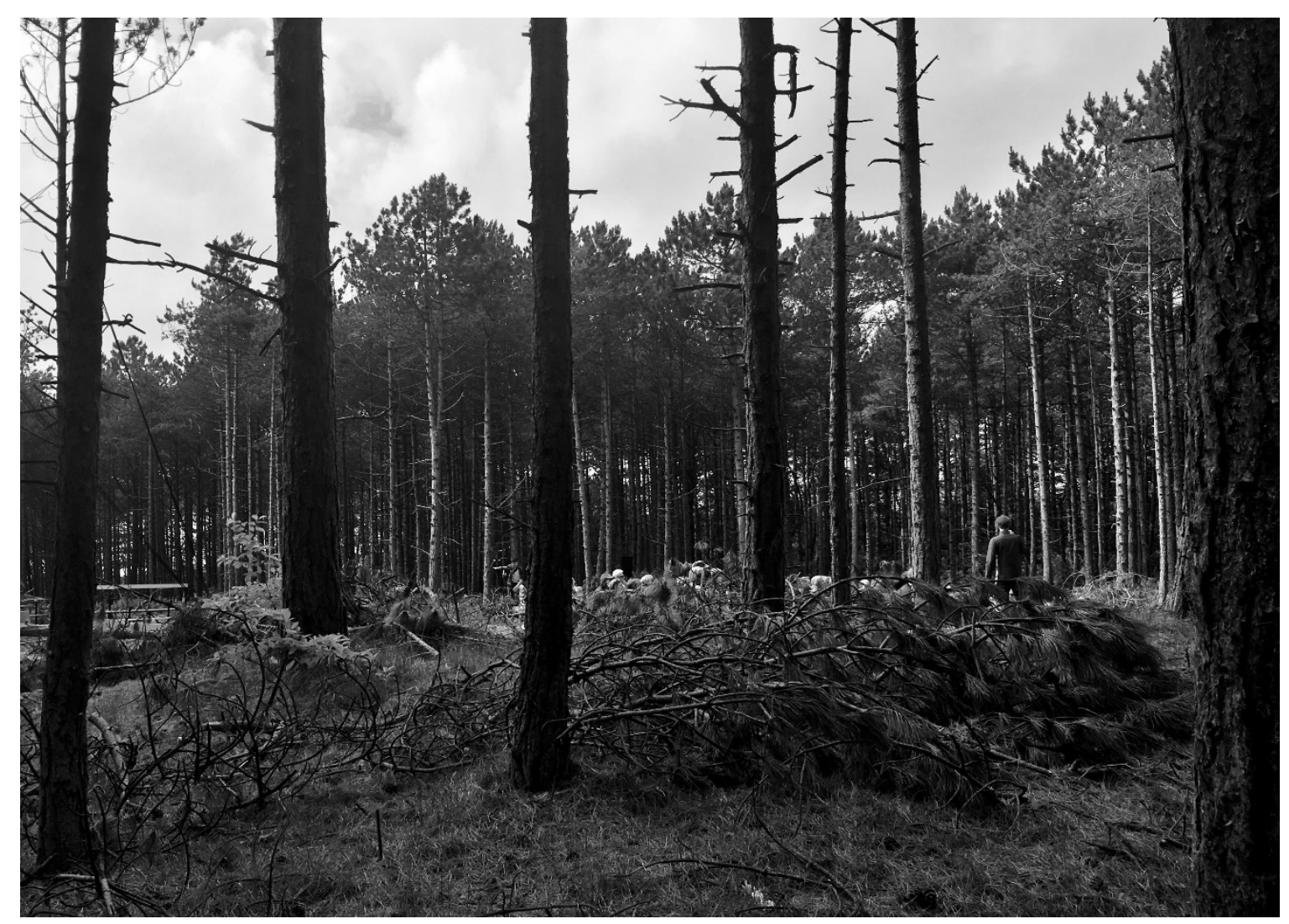

Figure 9. Artistic Acupuncture, Terschelling. Joanne Leighton. Photo (C) Joanne Leighton.

\section{Conclusions}

The different reflections that emerged from the Artistic Acupuncture missions, the analysis of its importance as a methodological tool, and the different challenges that were pointed out, lead us to make some final observations about this experimental 
methodology aiming to connect arts and the civil society and to tackle issues that our contemporary society faces.

By giving an important weight to the process, carefully avoiding the pressure to achieve rapid, concrete results, the Artistic Acupuncture in public space opens up new fields of practice and research through a rich and multi-layered approach. The main values reside in this constant process of inquiry and exploration; in the development of strategies of involvement and collaboration; in building fruitful interrelations between artists, cultural professionals, local authorities, citizens and communities at large; and in a practice that gives much value to the meaningful and constructive dialogue and exchange between people and places.

The Acupuncture missions are tools to interrogate an emerging landscape, crossed by diverse and difficult challenges that need to be addressed through different perspectives. The artists act as therapists - connecting again with the curative origin of the term acupuncture - by intervening in situations which are often blocked and need a fresh new gaze on them.

The participatory aspects of art and many other elements discussed are not new in the field of contemporary art, but the focus on public space through the acupuncture methodology does certainly provide alternative visions and strategies to operate from, beyond the more established canons in a highly complex and fast changing ecosystem. As expressed by Pierre Sauvageot, artist and director of Lieux publics: "It is urgent to invent new modes of exchange". ${ }^{4}$ Art in public space is therefore the field in which we can explore the deeper reality of collaborative, participatory and relational practices. By way of including and relating, this specific art field provides expanded practices that bring together many actors in a process of constant re-contextualization.

Along this experienced journey, the Acupuncture projects have opened the way to a more integrated approach in which artists connect with different layers of civil society. In this process, as stated by Jeanne van Heeswijk: "We need to think about how to break the artistic persona into a multiplicity of being as well, to unlearn the ways of inserting our skills, in order to ensure that people don't just become service 'users' of another kind, but rather that they are part of the building process, and thereby become true co-creators" (Van Heeswijk, 2016, p. 50).

Taking care of public space requires a system of new alliances with a plurality of perspectives and, if public space is a space for caring, we should therefore look at the whole world as public space. There is no doubt that this will be better shaped by the visionary contributions of artists.

\section{References}

Baltà Portolés, J. (2019) 'Cultural policies, the right to the city and the right to difference: reflections on the Agenda 2 I for culture,' in: Garcia-Chueca, E. \& Vidal, L. (Eds.), Advancing urban rights. Equality and diversity in the city, CIDOB, Barcelona, 2019. Available at: https://www.cidob.org/en/publications/publication_series/monographs/monographs/adva ncing_urban_rights_equality_and_diversity_in_the_city[Accessed 10 September 2020]

Bennoune, K. (2019). Cultural rights and public spaces. Report of the Special Rapporteur in the field of cultural rights. United Nations. Available at: https://undocs.org/en/A/74/255 [Accessed 10 September 2020]

\footnotetext{
${ }^{4}$ Interviewed by the author. 13th May 2020.
} 
Casanova, H. \& Hernández, J. (20I5). Public Space Acupuncture. Strategies and Interventions for Activating City Life, Actar.

Charter of Public Space (20/3). Rome. Available at: http://www.biennalespaziopubblico.it/outputs/the-charter-of-public-space/ [Accessed 10 September 2020]

Daniel, K. (2016), Public Spaces: A key tool to achieve the Sustainable Development Goals, HealthBridge. Available at: https://healthbridge.ca/images/uploads/library/Final_Electronic.pdf [Accessed I0 September 2020]

Garau, P. (20 I4). Public Space: a Strategy for Achieving the Equitable City. The UCLG Committee on Urban Strategic Planning. Available at: https://www.uclg.org/sites/default/files/uclgpublic_space-think_piece.pdf [Accessed 10 September 2020]

Lerner, J. (20I4). Urban Acupuncture, Island Press.

O'Donnell's, D. (2002). Social Acupuncture, Coach House Books.

Van Heeswijk, J. (20I I). Art and Social Change: learning collectively to take responsibility. Available at: http://www.jeanneworks.net/essays/art_and_social_change\%3A_learning_collectively_to ta ke_responsibility/ [Accessed I0 September 2020]

Van Heeswijk, J. (2016) 'Preparing for the non-yet', in: Pais, A.P. \& Strauss, F.C. (Eds.), Slow Reader, A Resource for Design Thinking and Practice. Valiz, Amsterdam. Available at: http://www.jeanneworks.net/files/esy/i_0025/JW_2016_SlowReader_PreparingForTheNonY et.pdf [Accessed 10 September 2020]

UCLG, (20I5). Culture 2I: Actions. Commitments on the role of culture in sustainable cities. Available at: http://agenda2I culture.net/sites/default/files/files/culture2I-actions/c2I 015 en.pdf [Accessed I0 September 2020]

UN Women Report (2017). Safe Cities and Safe Public Spaces. Available at: https://www.unwomen.org/Imedia/headquarters/attachments/sections/library/publications/2017/safe-cities-and-safepublic-spaces-global-results-report-en.pdf?la=en\&vs=45 [Accessed I0 September 2020] 